\title{
دور الجهات القضائية في تنفيذ عقوية الخدمة للنفع العام في التشريع \\ الجزائري
}

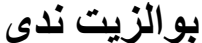 \\ كلبة الحقوق

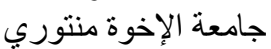 \\ قسنطينة
}

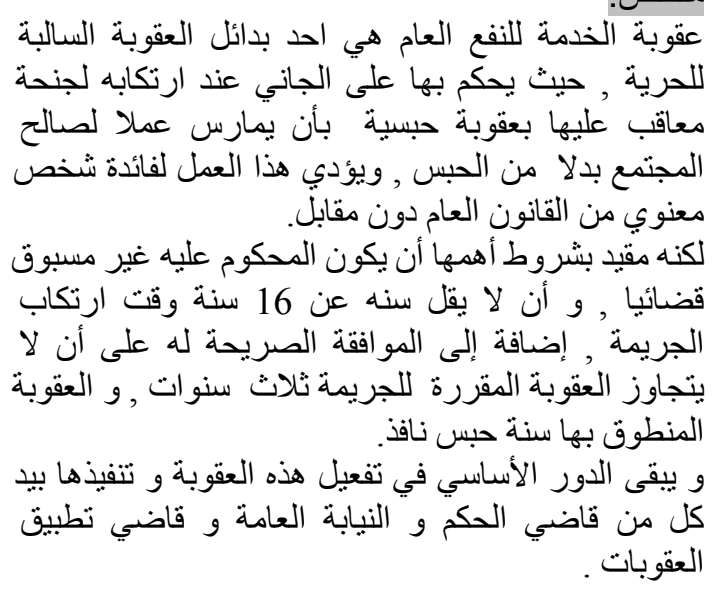

عقوبة الخدمة للنفع العام هي احد بدائل العقوبة السالبة

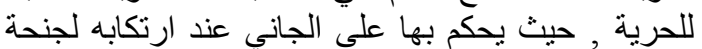

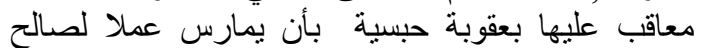

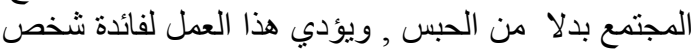
معنوي من القانون العام دون مقابل.

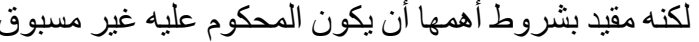

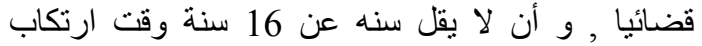

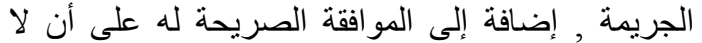

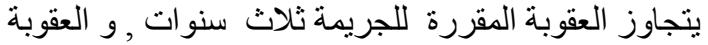
المنطوق بها سنة حبس نافذ.

و يبقى الدور الأساسي في تفعيل هذه العقوبة و تنفيذها بيد

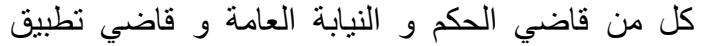

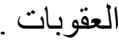

\section{Abstract:}

إذا كـان الهـدف مسن تتفيـذ الأحكــام

The community service is among the alternatives of the custodial sentence. It is pronounced in the case of commission of an offence liable to imprisonment, in order to perform community service for the benefit of a legal person of public law, provided that the following conditions are fulfilled:

The accused must have no criminal record and is at least 16 years old at the time of commission of the alleged infraction, the penalty for the offence shall not exceed three (3) years of imprisonment and the sentence shall not exceed one (1) year of imprisonment.

However, the main role in the implementation and execution of this sentence remains in the hands of the judge, the general prosecutor and the judge responsible for the execution of sentences. 


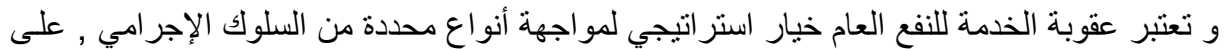

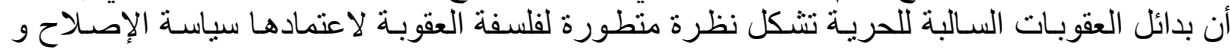

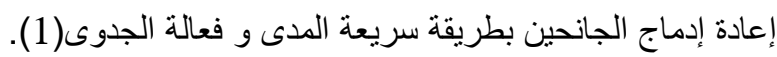

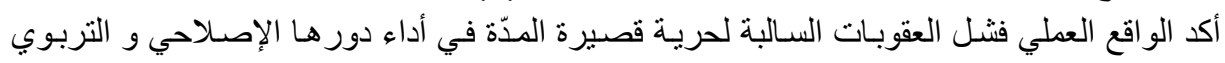

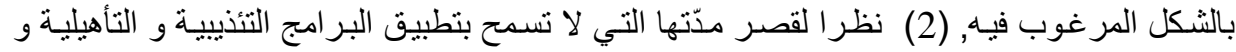

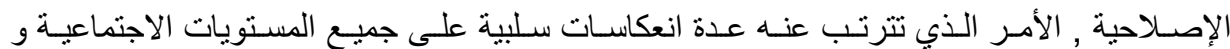

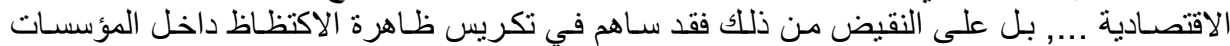

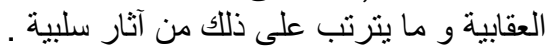

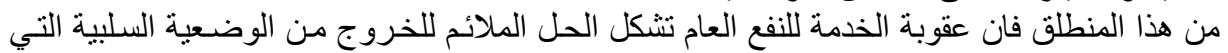

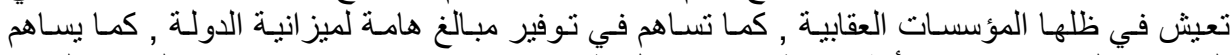

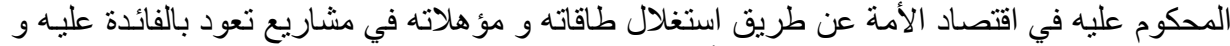

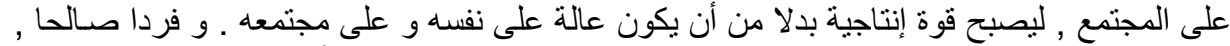

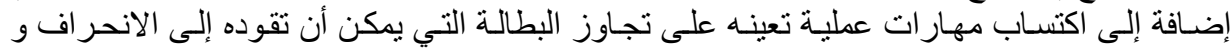

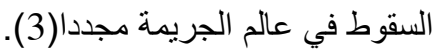

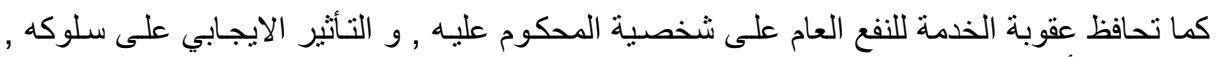

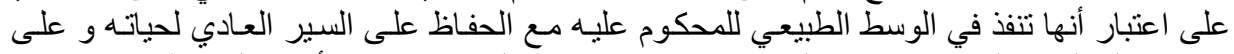

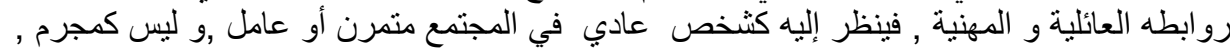

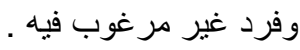

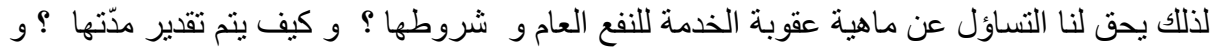

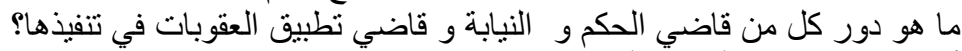
أولا : تعريف عقوبة الخدمة للنفع العام

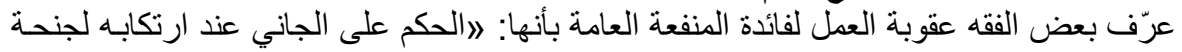

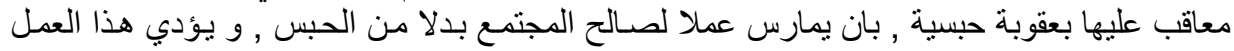

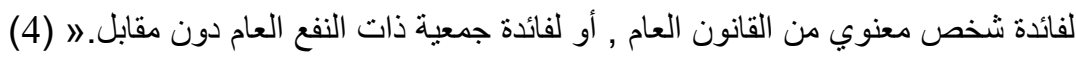

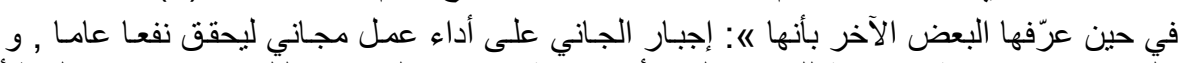

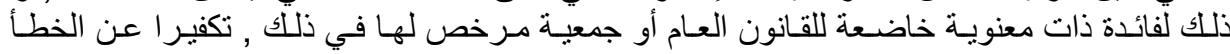

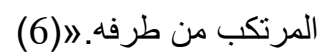
إذا كانت عقوبة العمل لفائدة النفع العام قد ظهرت حديثا في صورة أكثر تجديدا و التي اعتمدتها

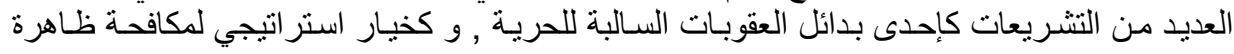

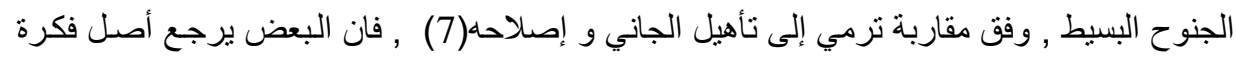

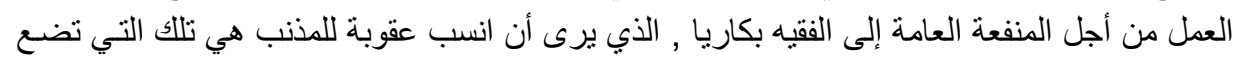

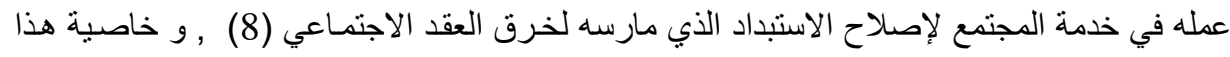

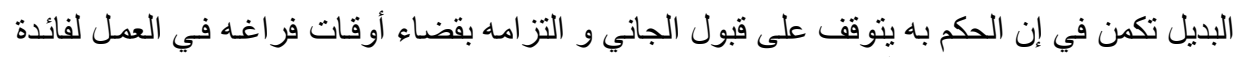

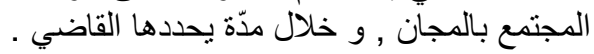

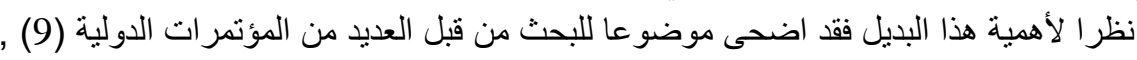

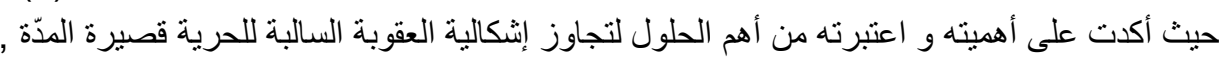

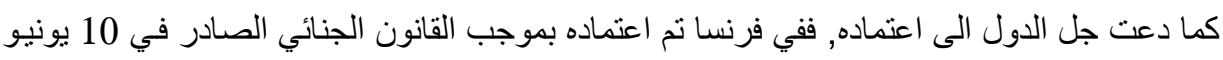

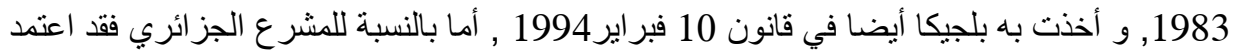


عقوبة العمل للنفع العام على غرار معظم التثريعات بموجب القانون رقم 01-09 المؤرخ في 25 فبر اير 2009 المنضمن كيفية تطبيق عقوبة العمل للنفع العام بحيث خصص لها المو اد من 05 مكرر

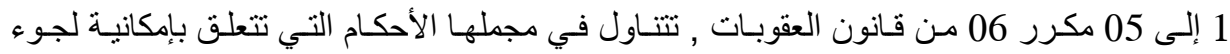

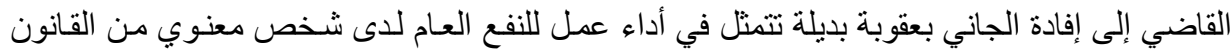

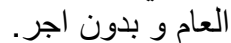

ثناتيا: شروط الحكم بعقوبة العمل للنفع العام

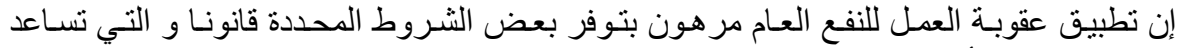

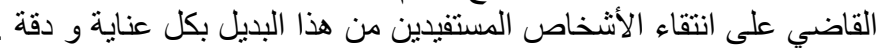

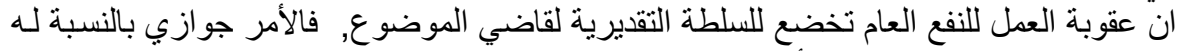

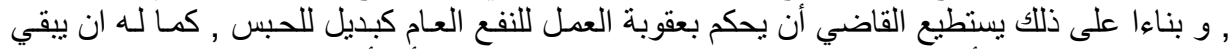

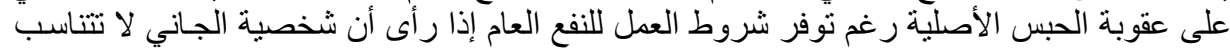

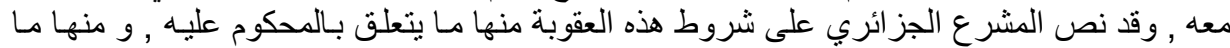

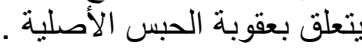

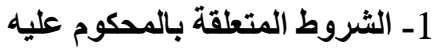

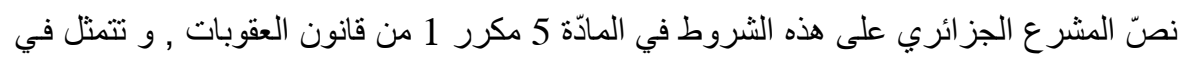

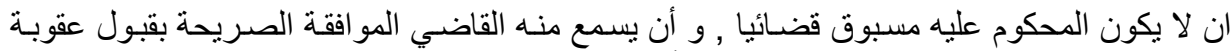

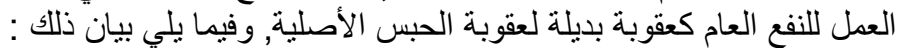

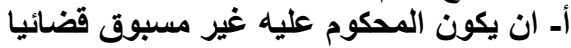

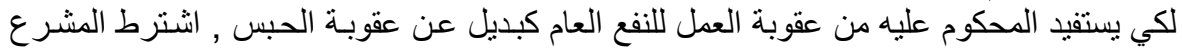

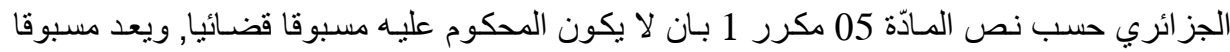

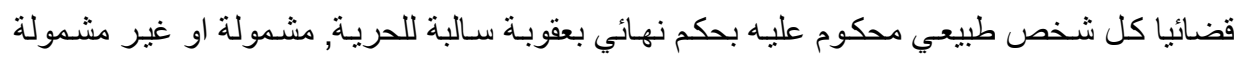

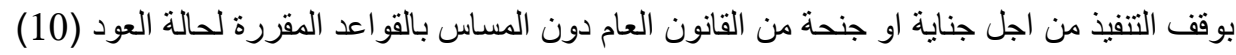

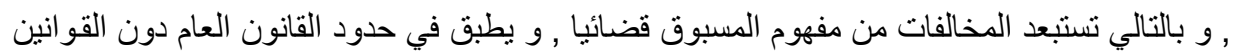

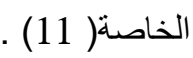

و يتم التأكد من أن المحكوم عليه غير مسبوق قضائيا أو لا عن طريق صحيفة السو ابق القضائية

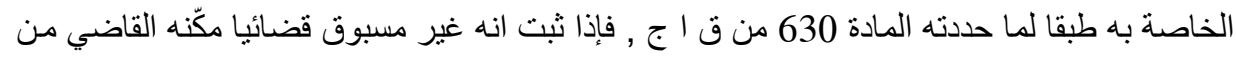

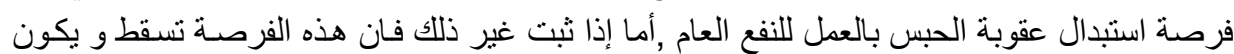

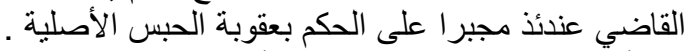

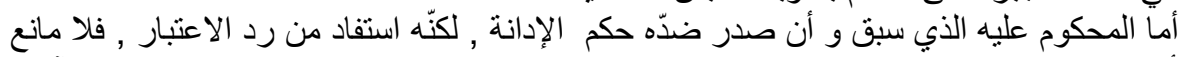

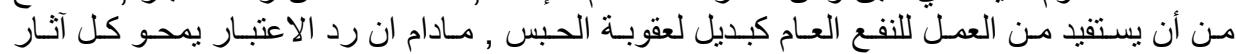

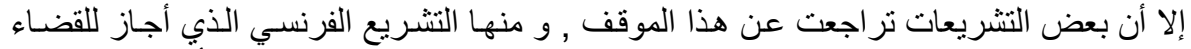

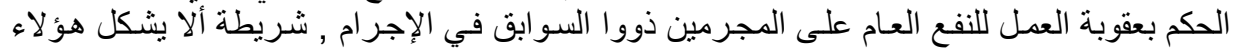

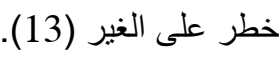

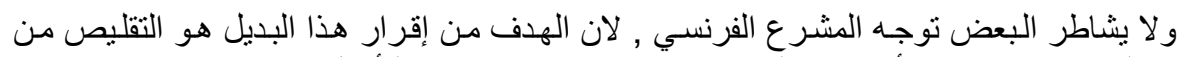

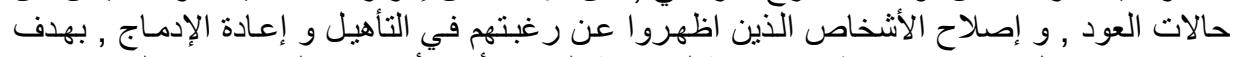

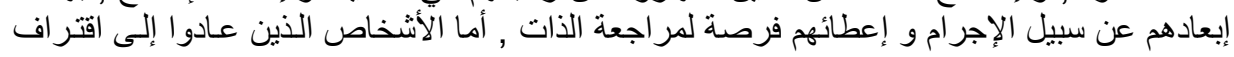


الجريمة مرّة ثانية فلا يرجى منهم الإصلاح , لان حالة العود تعبر عن فنل شخصبة الجاني في التأهيل , و هذا ما أكدته دراسات في علم الاجر ام (14).

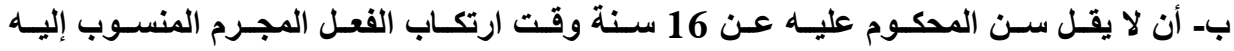

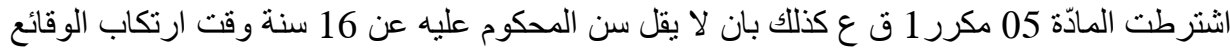

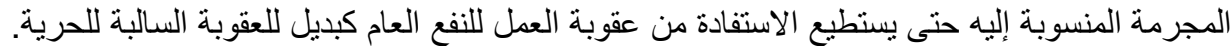

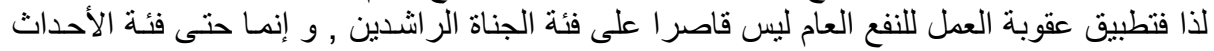

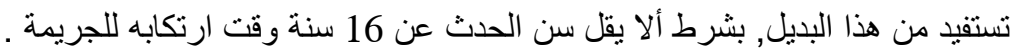

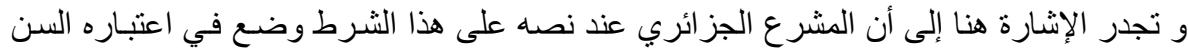

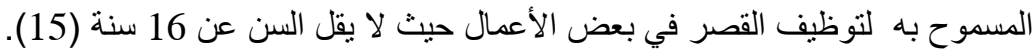
ج-الموافقة الصريحة للمحكوم عليه.

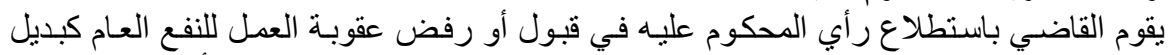

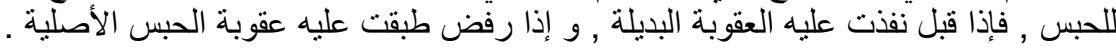

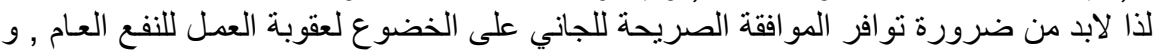

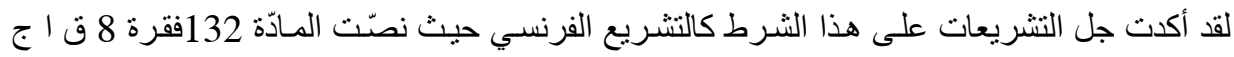

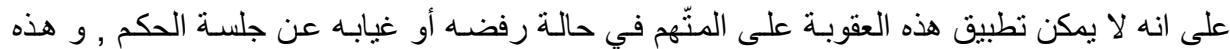

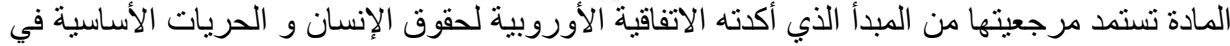

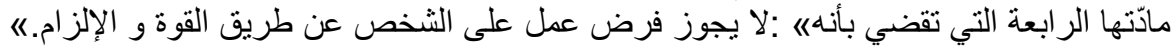

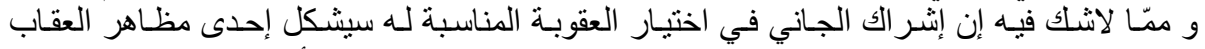

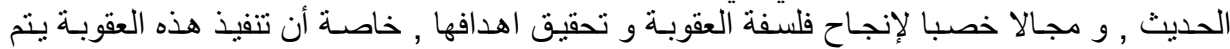

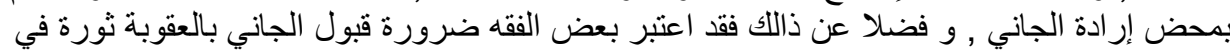

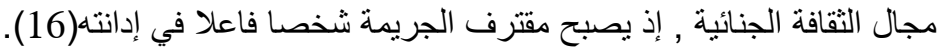

2-الثروط المتعلقة بالعقوبة الأصلية

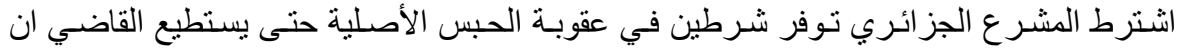

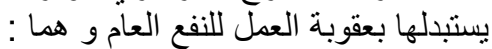

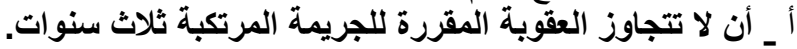

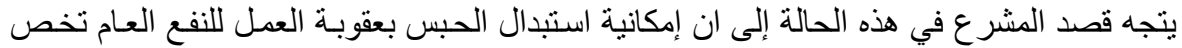
الجرائم البسيطة دون غير ها , و بالرجوع إلى نص المادة 5 ق ع نجد أن المشر ع استبعد كل العقوبات الكات

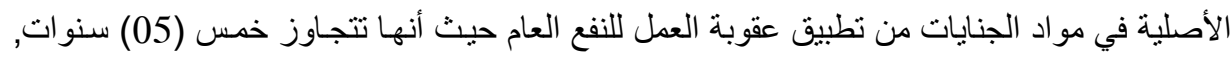

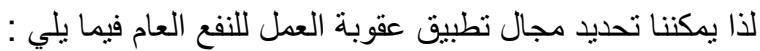
-

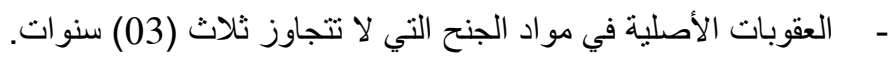

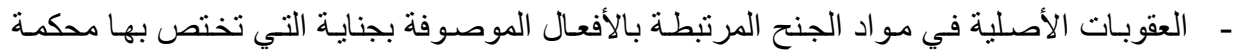

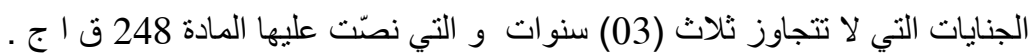

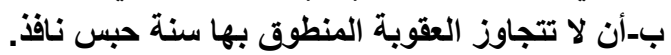

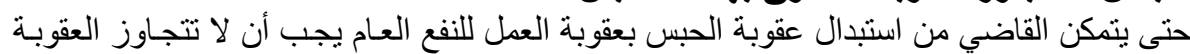

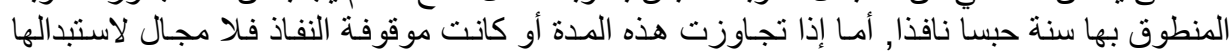

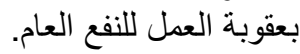


لقد نص المنشور الوزاري رقم 02 المؤرخ في 29 افريل 2009 الذي يوضح كيفيات نطبيق عقوبة

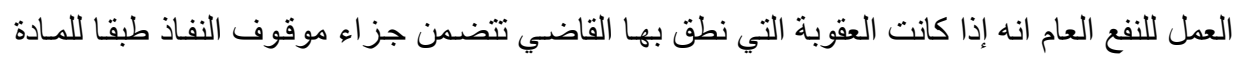

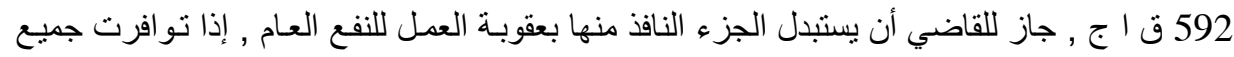

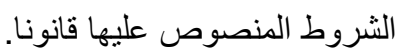

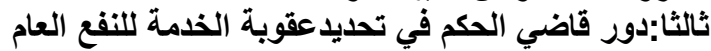

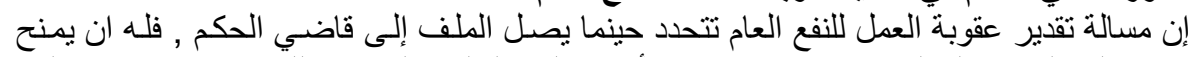

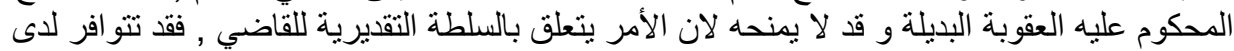

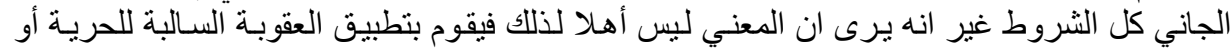

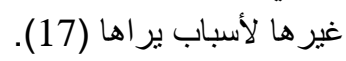

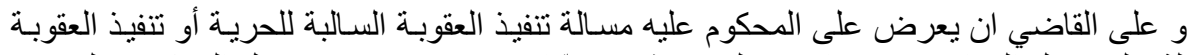

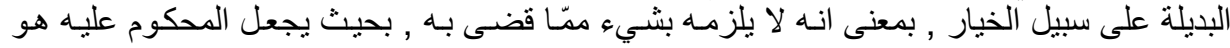

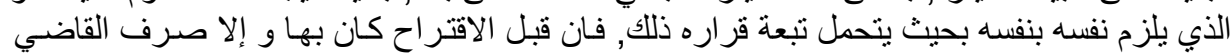

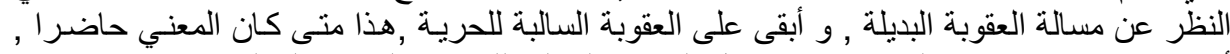

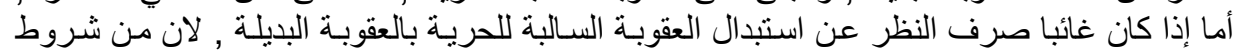

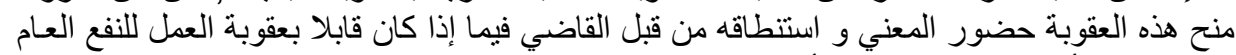

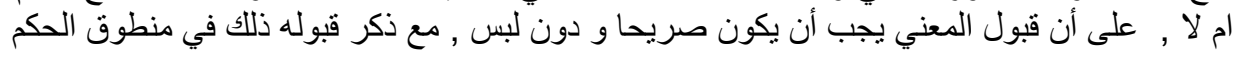

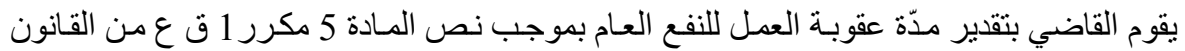

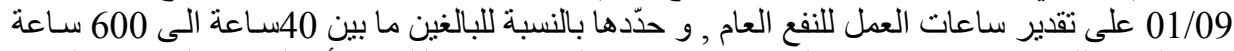

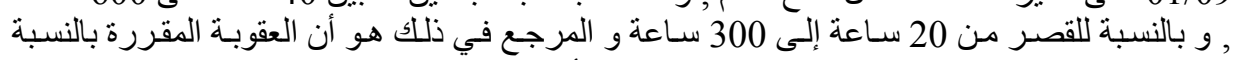

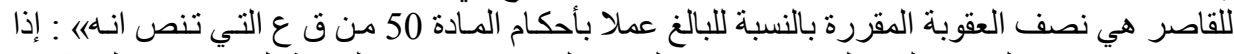

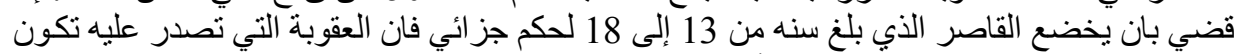

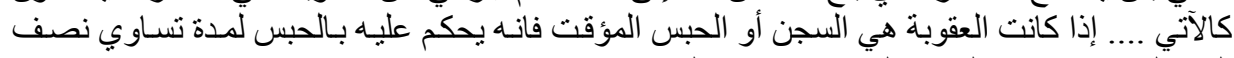

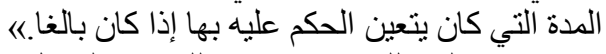

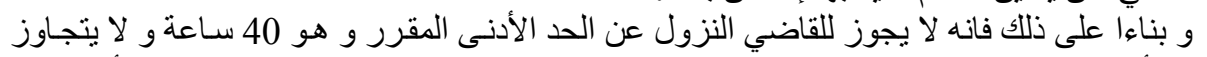

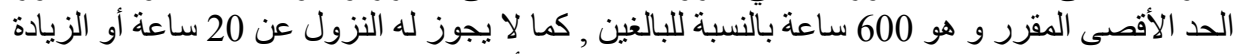

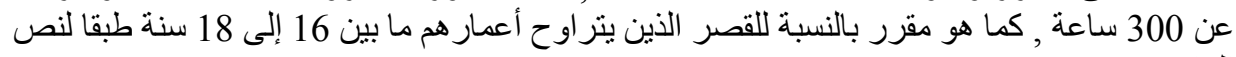

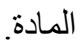

إن المعيار الذي وضعه المشرع الجزائري لاحتساب الساعات المتعلقة بالعمل للنفع العام هو احتساب

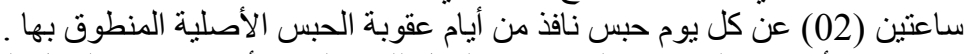

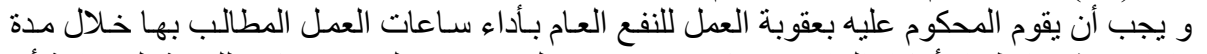

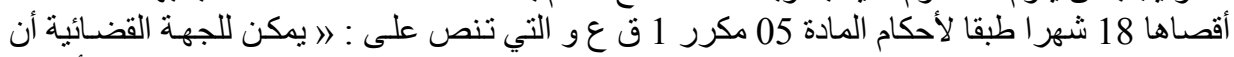

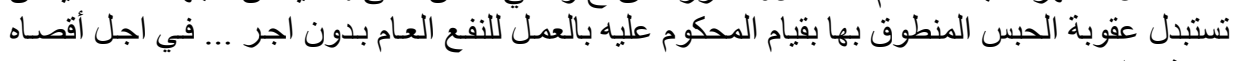
18 18 و يبدأ سريان هذه المدة مباشرة بعد أن يصبح الحكم بعقوبة العمل للنفع العام نهائيا , أي بعد استنفاذ جميع طرق الطعن (19).

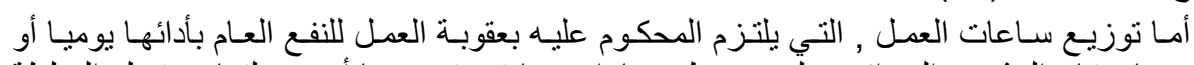

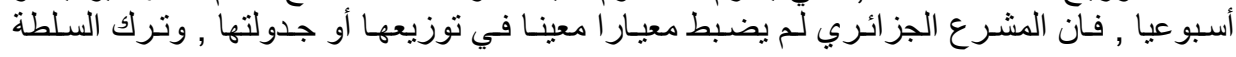

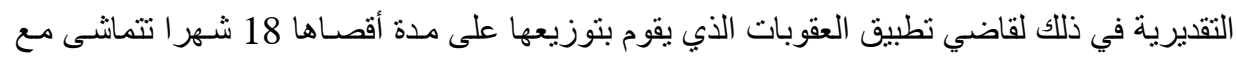


ظروف المحكوم عليه و مؤهلاته و قدر اته و أوقات فر اغه , و و كذا مع ظروف المؤسسة المستقبلة لـه ,

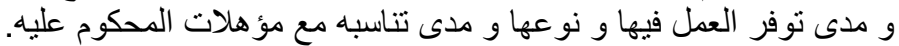
رابعا: دور النيابة العامة في تنفيذ عقوبة فو العمل للنفع العام.

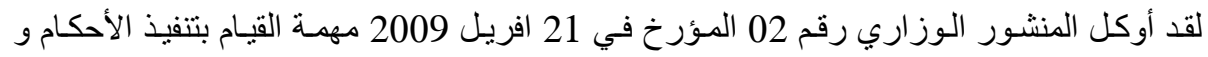

القرار ات المتعلقة بعقوبة العمل للنفع العام للنائب العام المساعد على مستوى المجلس , و و لا تتفذ عقوبـة المبة

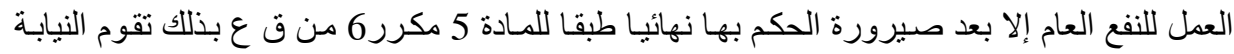

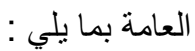

\section{1- التسجيل في صحيفة السوابق القضائية.}

-تقوم النيابة العامة بإرسال قسيمة السوابق القضائية رقم 01 متضمنة العقوبة الأصلية مع الإرشـاد إلى

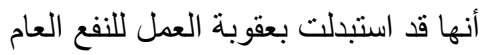
- يتم التسجيل على القسيمة رقم 02 العقوبة الأصلية و عقوبة العمل للنفع العام البديلة . - يتم تسليم القسيمة رقم 03 خالية من الإشارة إلى العقوبة الأصلية و عقوبة العمل للنفع العام.

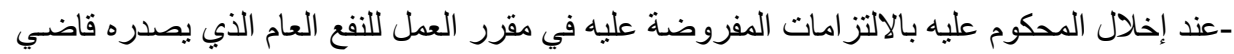

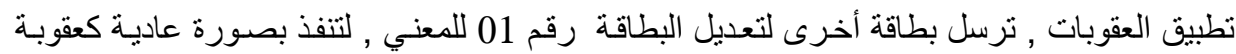
حبس نافذ مع تقييد ذلك على هامش الحكم أو القرار القضائي.

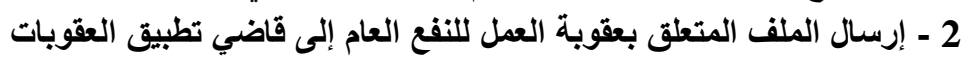

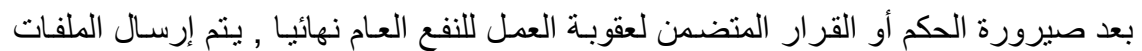

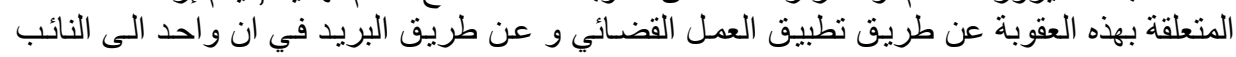

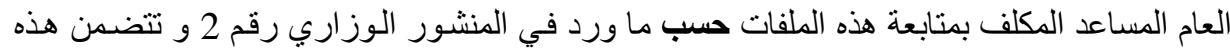

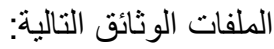

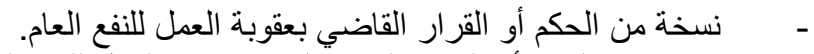

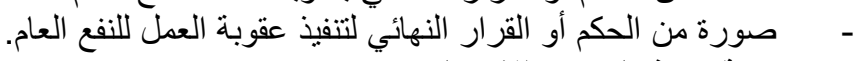

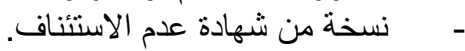
-

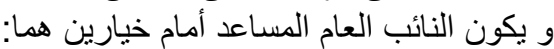

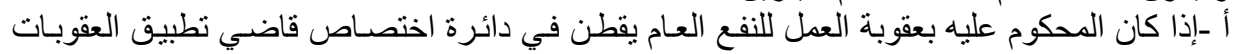

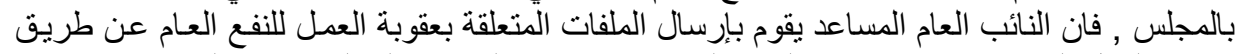

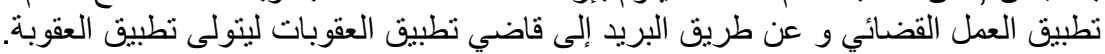

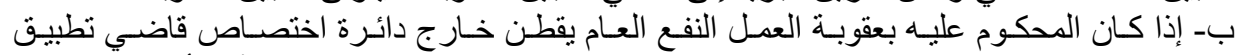

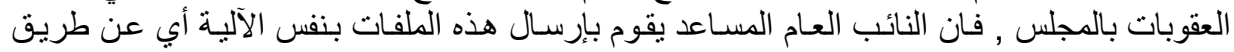

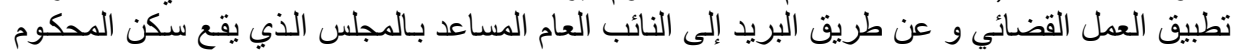

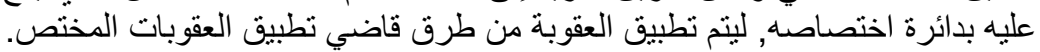

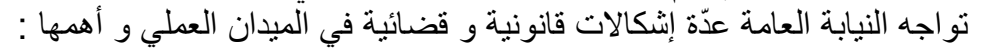

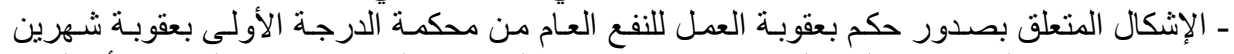

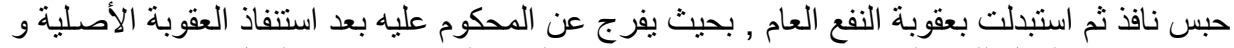

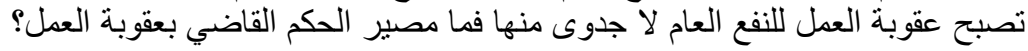




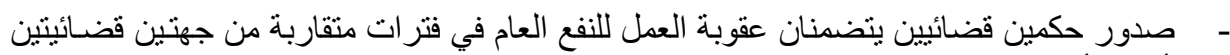

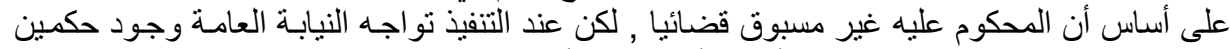

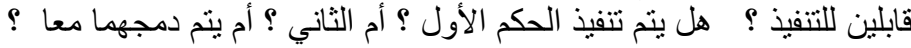

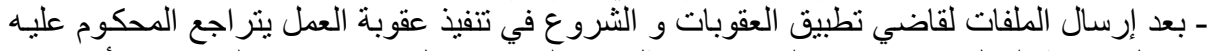

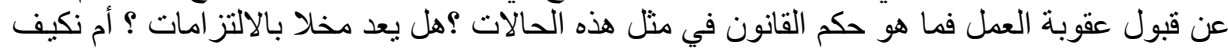

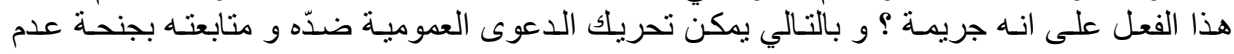

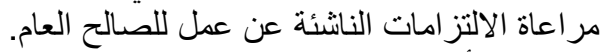

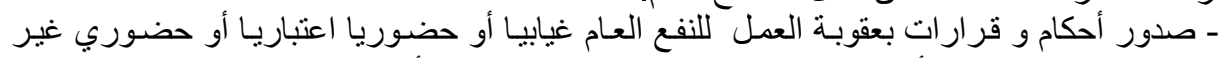

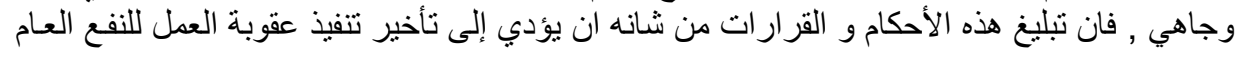

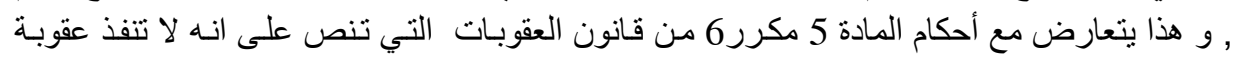

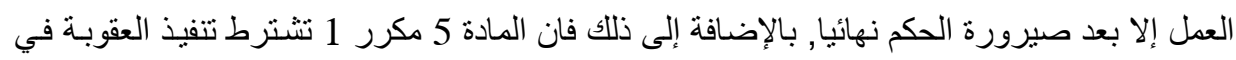

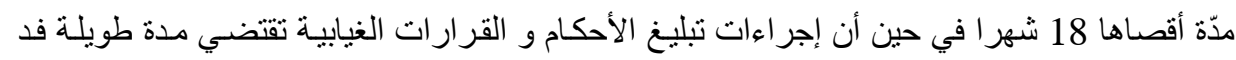

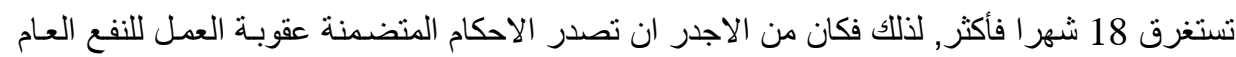

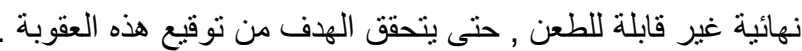

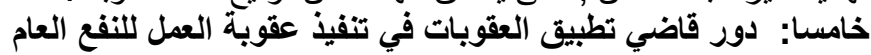

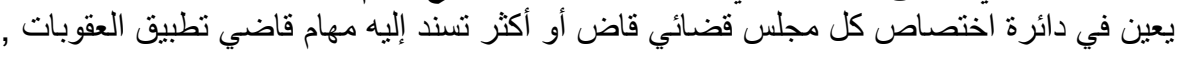

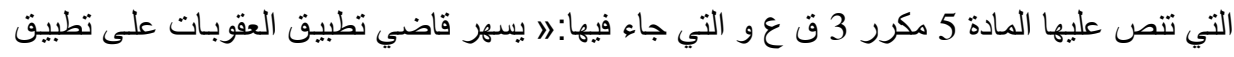

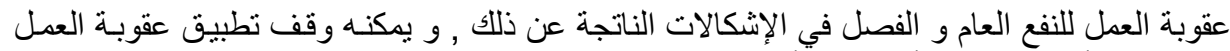

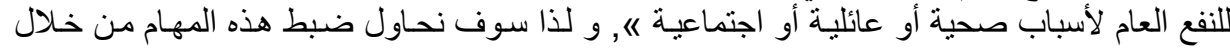

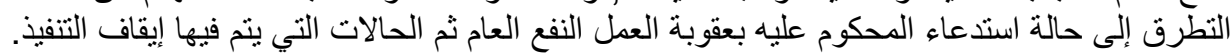

\section{1 - استدعاء المحكوم عليه بعقوبة العمل للنفع العام}

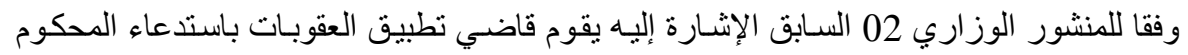

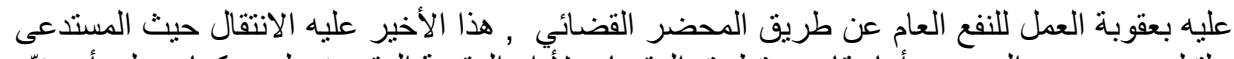

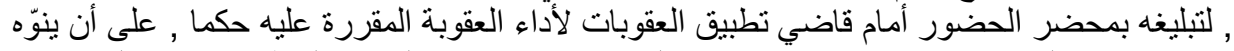
قاضي تطبيق العقوبات في الاستدعاء انه في حالة عدم حضوره في التاريخ المحدّد ستطبق عليه عقوبة الطية

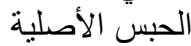

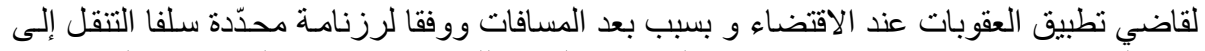

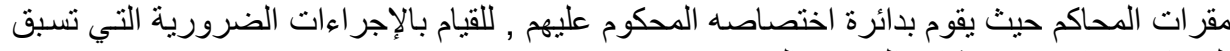
الاتنفيذ ,و هنا يتعين الإشارة إلى احتمالين:

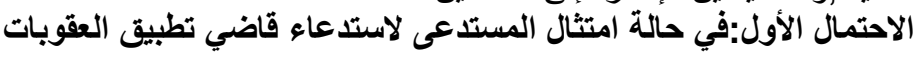

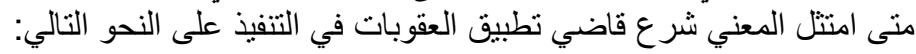
1- التأكد من هوية المعني و ذلك باستظهار بطاقة التعريف القانونية.

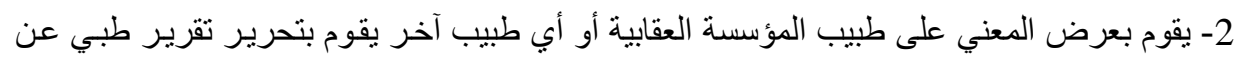

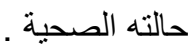

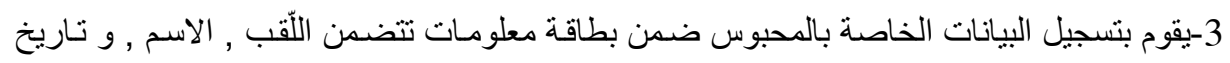

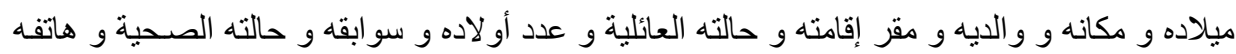

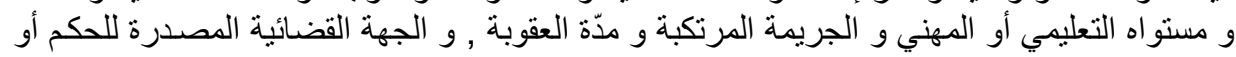


القرار , و تاريخ الحكم أو القرار و رقمه , و رغباته و الجهة الدحدة و المكان و التوقيت و أخيرا مدّة

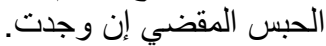

4 -يحرر مقرر الوضع الذي يتضمن ترسانة من المعلومات , منها رقم المقرر و تاريخ الحكم و رقمـهـ

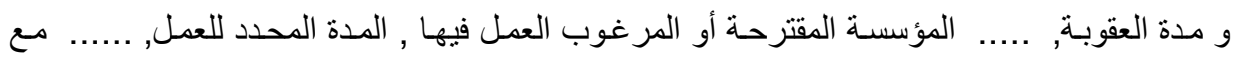

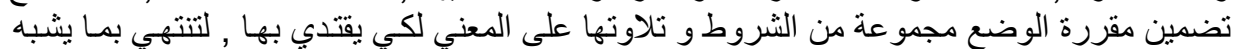

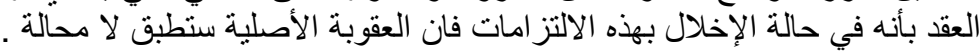

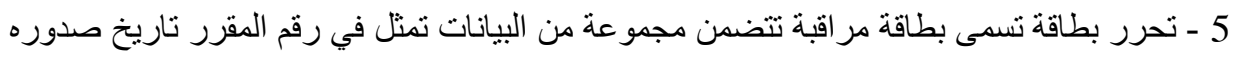

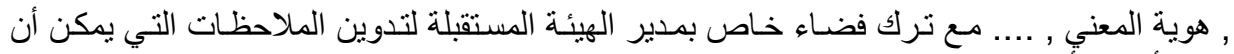

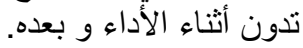

6 - تحرير بطاقة الإمضاء التي يتعين على المعني التوقيع عليها دخو لاو و خروجا . 7 ـ تحرير المر اسلة أو الإرسالية على (03) نسخ بحيث نوزع على على الجهات ذاتئ عات الصلة على النحو

* التالي: نسخة ترسل بمعية المستفيد إلى مدير أو رئيس المؤسسة المعنية بالاستقبال .

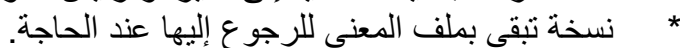

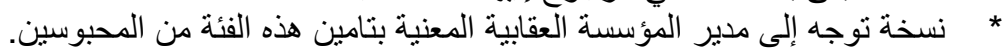

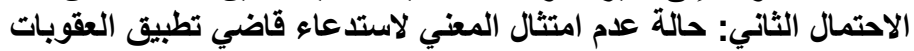

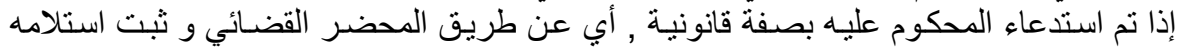

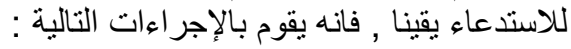

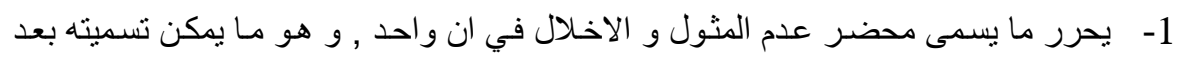

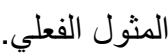

2- يحيل ملف المعني إلى النيابة العامة مرفقا بذلك المحضر , و ذللك للتصرف فيه وفق مقتضيات

القانون , و هي تنفيذ العقوبة الأصلية. 2-

تنتهي عقوبة العهل للنفع العام تلقائيا بأداء المحكوم عليه الالتزامـات أو عند إخلاله بالالتزامـات المترتبة على هذه العقوبة.

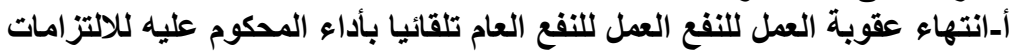

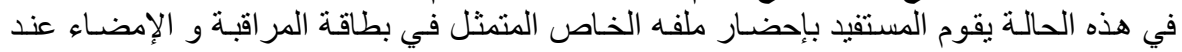

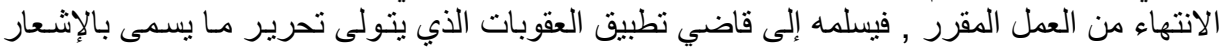

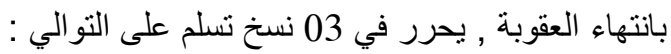
* * ن *نخة تبقى في ملف المعني. * * ن نسخة تسلم إلى المعني شخصيا.

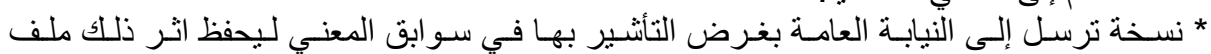

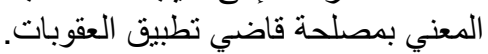
بـ انتهاء عقوبة العمل للنفع العام بسبب إخلادل المحكوم عليه بالالتزامـات.

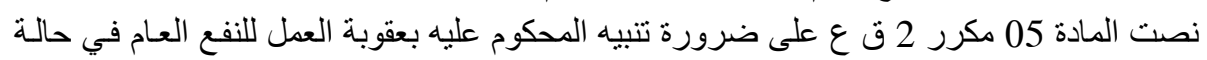
إخلاله بالالتزامات المترتبة على هذه العقوبة البديلة , فانه ستطبق عليه عقوبة الحبل الحبس الأصلية و يمكن حصر هذه الإخلالات في : الإنية - أن لا يلتحق المعني أصلا بالمؤسسة التي عين بها. 
- أن يلتحق و ينم تتصيبه ثم يغادر إلى غير رجعة .

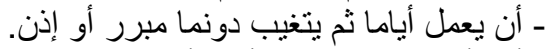

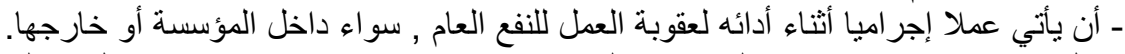

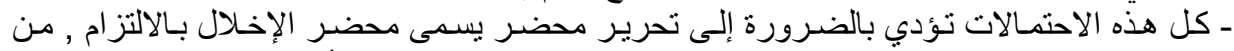

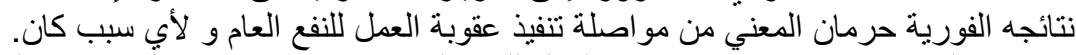

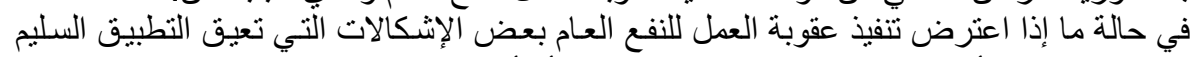

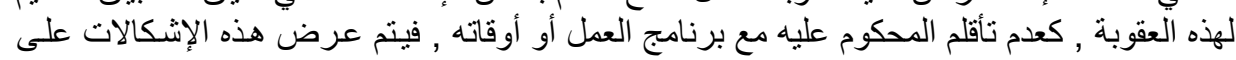

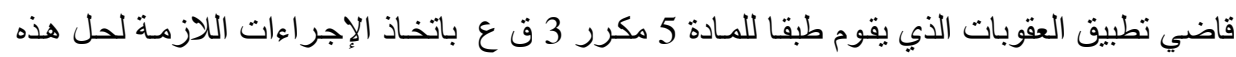

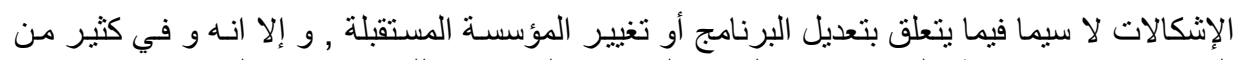

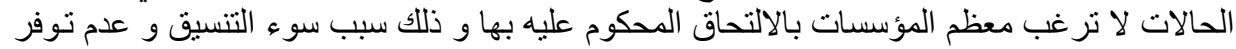
شروط تنطلابها هذه المؤسسة.

القاضي تطبيق العقوبات كذللك إمكانية وقف تطبيق إنبات عقوبة العمل للنفع العام لأسباب صحية أو عائلية

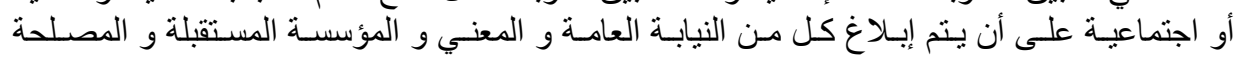

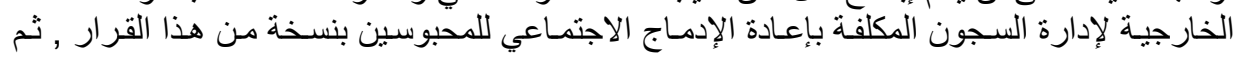

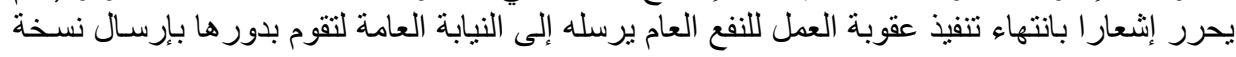

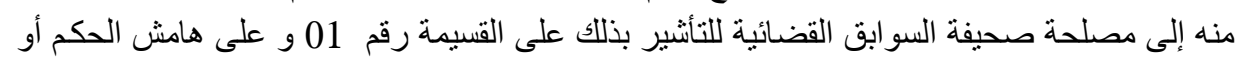

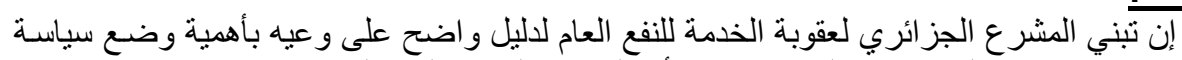

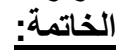

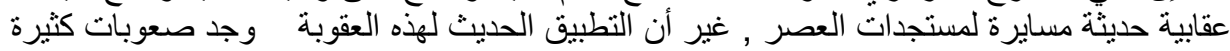

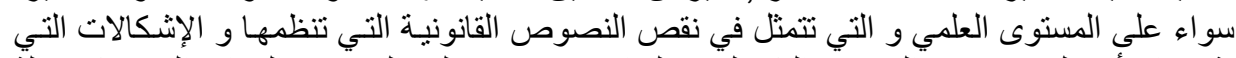

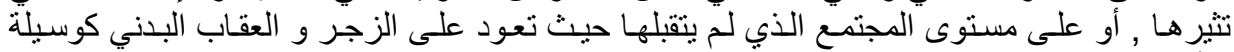

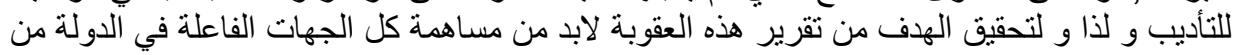

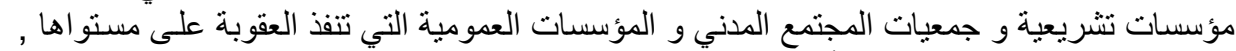

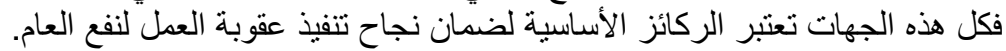

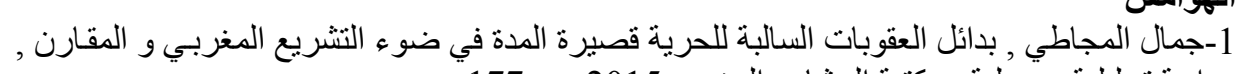

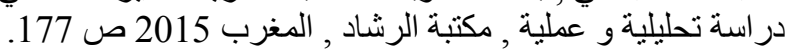

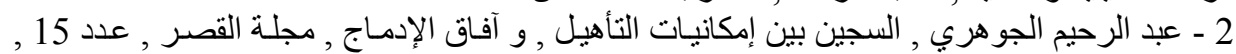

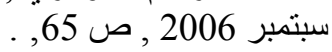
3 - رياض عبد الغاني , بدائل العقوبات في القانون المغربي و القانون المقارن و أفاقها المستقبلية ,

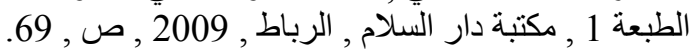
jean - Christophe , le guide des infractions ,hunième édition , 2007, Dalloz -4 .,p353

5 - بوجمعة الزناكي , بدائل العقوبات السالبة للحرية , الشغل من اجل المنفعة العامة , مجلة الإشعاع '

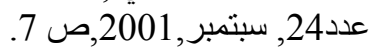

6 - ابو لبابة العثماني , النظام القانوني لعقوبة العمل لفائدة المصلحة العامة كبديل عن العقوبة السجنية ,

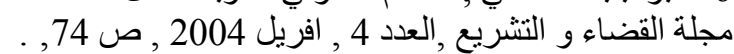
7 - عطية مهنا , دور العمل في تأهيل السجون , دراسـة مقارنـة , الدجلة الجنائية القومية , العدد 3 , ر نوفمبر 2007 ,ص ص 233. 


$$
\text { بو الزيت ندى }
$$

jean pradel, les nouvelles alternatives à l'emprisonnement créés par la loi du -8 .10 juin 1983 , in recueil Dalloz 1984. P 117

9 ـ كالمؤتمر الدولي الثاني للامم المتحدة لمكافحة الجريمـة و معاملـة المجرمين ’ المنعقدة بلندن سنة

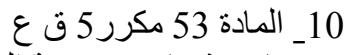

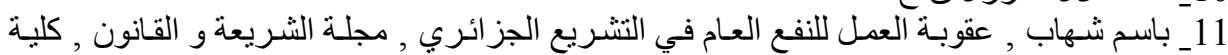

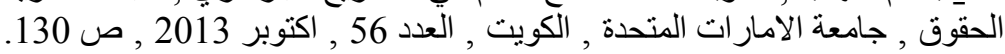

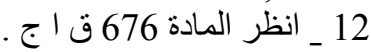
.jean .christophe ,op.cit.p 352-13

14 ـ فتوح عبد الله الثـادلي , أساسيات علم الإجر ام و العقاب , منشاة المعارف الإسكندرية , ,2000 ص ص 114

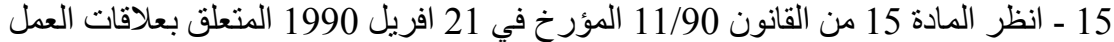

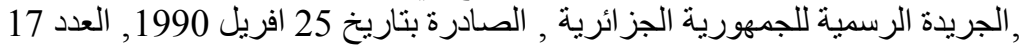

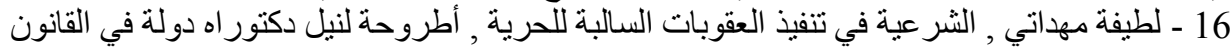

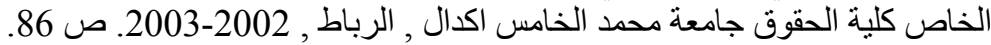

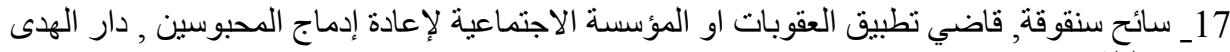

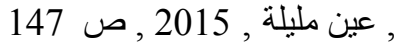
18 ـ المرجع نفسه , ص148 148

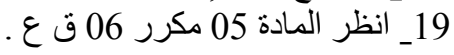

